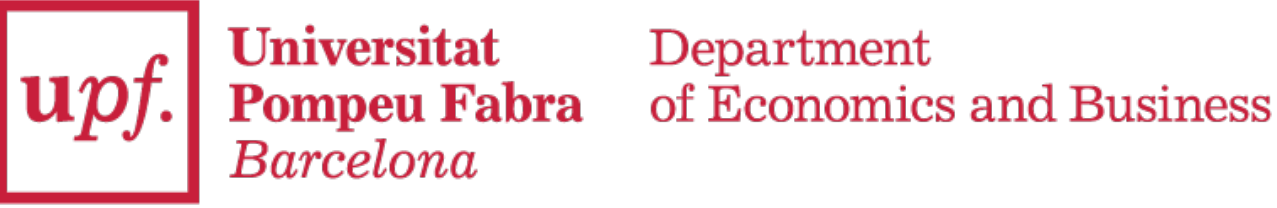

Economics Working Paper Series

Working Paper No. 1588

\title{
Property rights in sequential exchange
}

Benito Arruñada, Giorgio Zanarone, and Nuno Garoupa

November 2017 


\title{
Property Rights in Sequential Exchange
}

\author{
Benito ARRUÑADA*, Giorgio ZANARONE ${ }^{* *}$, and Nuno GAROUPA ${ }^{* * *}$
}

November 2017

\begin{abstract}
We analyze the "sequential exchange" problem in which traders have incomplete information on earlier contracts. We show that under sequential exchange, it is in general not possible to simultaneously implement two key features of markets - specialization between asset ownership and control, and impersonal trade. In particular, we show that in contrast with the conventional wisdom in economics, strong property rights - enforceable against subsequent buyers - may be detrimental to impersonal trade. Finally, we provide conditions under which a mechanism that overcomes the tradeoff between specialization and impersonal trade exists, and we characterize such mechanism. Our results provide an efficiency rationale for how property rights are enforced in business, company and real estate transactions, and for the ubiquitousness of "formalization" institutions that the literature has narrowly seen as entry barriers.
\end{abstract}

Keywords: Property rights, Enforcement, Contracts, Incomplete information, Impersonal exchange

JEL codes: D23; D83; K11; K22

\footnotetext{
*Universitat Pompeu Fabra and Barcelona GSE; e-mail: benito.arrunada@upf.edu. Colegio Universitario de Estudios Financieros; e-mail: gzanarone@cunef.edu. ${ }^{* * *}$ Texas A\&M University School of Law \& Católica Global School of Law; e-mail: nunogaroupa@law.tamu.edu. We thank Agustín Casas, Pablo Casas-Arce, Oscar Contreras, Carlos Gómez-Ligüerre, Carmine Guerriero, Stephen Hansen, Daniel Herbold, Thomas Merrill, Jens Prüfer, Alan Schwartz, Henry Smith, Giuseppe Zanarone, and audiences at the ALEA and SIOE conferences as well as George Mason University, Washington and Lee University, and HKU Faculty of Law for useful comments. This study received financial support from the Spanish Ministry of Economy and Competitiveness through grant ECO201457131-R and the Severo Ochoa Program for Centers of Excellence in R\&D (SEV-2015-0563). Usual disclaimers apply.
} 


\section{Introduction}

From Coase (1960) to Akerlof (1970), Williamson (1979), and Grossman and Hart (1986), economic models assume that transactors are well informed on the allocation of property rights prior to contracting. While this assumption is useful to keep formal analysis tractable and pedagogical to frame the discussion, it contradicts the reality of modern markets. Thus, a buyer of goods or land may not know whether she is buying from the owner, an agent of the owner, or a fraudulent seller. Similarly, a company's client, supplier, or investor, may ignore whether the manager she is dealing with has been previously authorized by shareholders to conduct that particular business on behalf of the company. As a result, transactors may acquire rights over an asset that are inconsistent with a prior allocation of rights established by potentially hidden contracts.

This article develops one of the first formal economic models analyzing the fundamental "sequential exchange" problem described above (an earlier important model is Ayotte and Bolton, 2011. We discuss the two papers' distinctive yet complementary contributions in section 4.5). We argue that under sequential exchange, the central question is who should be allocated an asset in case of conflict - that is, whether rights over the asset should be enforced against subsequent buyers, as "property rights", or only against the seller, as "personal rights". We show that under these polar institutional regimes, it is in general not possible to simultaneously support two key features of markets - namely, specialization of asset ownership and control, and impersonal trade. ${ }^{1}$ We then provide conditions under which institutions that support both of these market features can be designed.

\footnotetext{
${ }^{1}$ In a different yet complementary paper, Kranton (1996) shows that the emergence of impersonal trade may also be discouraged by the existence of well developed reciprocal exchange channels.
} 
Our model consists of four overlapping stages. At the outset, principal P decides whether to keep control of his asset or delegate control to specialized agent $\mathrm{A}$, in which case the asset gains value but $\mathrm{P}$ is potentially exposed to $\mathrm{A}$ 's opportunism. At a second stage, P enters an "originative" contract with A, which defines A's authority to transfer P's asset in the future. At a third stage, A enters a "subsequent" contract over the asset with third party $\mathrm{T}$ (a buyer, or a seller on credit), who does not observe the originative contract between $\mathrm{P}$ and $\mathrm{A}$. We assume that transferring the asset to $\mathrm{T}$ is efficient but $\mathrm{P}$ cannot do it himself - that is, there are gains from impersonal (i.e., mediated by A) trade. At the fourth and final stage, if there is a conflict between the originative and the subsequent contract, a judge may allocate the asset to $\mathrm{P}$, in which case $\mathrm{P}$ has a property right (Merrill and Smith, 2000; Hansmann and Kraakman, 2002), or to T, in which case $P$ has a mere "personal" right — that is, a right to sue A for damages, which has little value if A has limited liability.

Our model has significant applications. In a property context, the asset may be P's estate, A may be P's tenant, and T a buyer to whom A may attempt to sell the estate. In a company context, the asset may be P's firm, A may be a manager, and $\mathrm{T}$ a client or a distributor. In a straightforward extension of the company case, $\mathrm{T}$ may also be a supplier who sells on credit to manager $\mathrm{A}$ relying on the firm's assets as a guarantee of payment.

We begin by showing that, in contrast with the conventional wisdom in economics (e.g., North and Thomas, 1973; Besley 1995), strong property rights may be detrimental to impersonal trade, and that sequential exchange generates a tradeoff between separation of ownership and control and impersonal trade. Intuitively, if property rights are unconditionally enforced, impersonal market transactions would fail because $\mathrm{T}$ would refuse to deal for fear that the asset's owner, P, and his agent, A, may have colluded to keep P's right hidden. At the same time, in the absence of property rights, T would deal with A regardless of P's authorization. Anticipating that, $\mathrm{P}$ may refuse to 
separate ownership and control of the asset, thereby forgoing the gains from specialization.

Having shown that property rights facilitate separation (i.e., specialziation) of asset ownership and control at the cost of discouraging market transactions, we then establish a simple efficiency test to determine under what conditions they should be enforced. According to such test, P should be granted a property right if, and only if it can be presumed that he has not authorized A to transfer the asset. We show that depending on the available technology, this test will be based on explicit or implicit evidence of P's authorization, generating more or less rigid definitions of property rights.

Suppose first that $\mathrm{P}$ can give explicit public notice of the originative contract at reasonable cost - for instance, by filing it in a registry that $\mathrm{T}$ can cheaply access. In that case, we show that it is efficient to grant $\mathrm{P}$ a property right if, and only if he has given notice that $\mathrm{A}$ is not authorized to contract over the asset. This mechanism achieves the first best - that is, it implements both separation of ownershipo and control and impersonal trade - because it removes both $\mathrm{P}$ 's and A's incentive to collude against $\mathrm{T}$, which exists under unconditional property rights, and T's incentive to deal with A regardless of P's authorization, which arises in the absence of property rights. This solution is best illustrated by the institutions developed by most legal systems to "formalize" property and businesses. Thus, many property rights over durable assets (including those on land, intellectual property and some financial securities) are valid against subsequent acquirers only if they are made public - historically, through conspicous ceremonies such as, for example, the mancipatio used in classical Roman law to transfer property; in more developed markets, by entering information in some sort of registry (Baird and Jackson, 1984; Ellickson and Thorland, 1995; Arruñada, 2003). Similarly, contracts signed by company representatives often commit the company only 
if they are recorded as such in a public registry (e.g., Armour and Whincop, 2007; Arruñada, 2010).

Suppose next that $\mathrm{P}$ cannot give public notice of the originative contract for instance, because developing a registry is too costly. In that case, we show that it is (second best) efficient not to give $\mathrm{P}$ a property right if given verifiable characteristics of the asset, or of the market where it is traded, there is a high likelihood that $\mathrm{P}$ would separate ownership and control of the asset, thus implicitly authorizing A to transfer it to third parties. All else equal, this is more likely to be the case the higher the gains from specialization of asset ownership and control, and the lower the agent's potential opportunistim. An example of how this rule is applied in practice is the law of good faith purchase (e.g., Medina, 2003; Arruñada 2010; Schwartz and Scott 2011). According to such rule, property rights on movable goods are not enforceable against subsequent buyers when purchased from a professional merchant, who has a market reputation and hence can be presumed not to sell against the owner's will. Another illustration is adverse possession (e.g., Lueck and Miceli, 2007; Arruñada, 2015), whereby the owner of an asset loses his property rights to parties who have subsequently purchased the asset from a long-term possessor, the passing of time being implicit evidence that the owner has delegated control of the asset to the possessor.

An important implication of our analysis is that, when public evidence of the originative contract can be produced at reasonable cost (Arruñada and Garoupa, 2005), enforcing property rights based on such evidence is the first best solution, because it allows owners the freedom to flexibly protect their assets without generating uncertainty for subsequent buyers. This has important implications for policy, as it suggests that formalization of business and property is not an entry barrier, as argued by De Soto $(1989,2000)$, Djankov et al. (2002), and the "Doing Business" project (World Bank, 2004- 
16), but a necessary condition for the effective functioning of property rights and market exchange.

The rest of this paper is organized as follows. Section 2 presents our sequential exchange model. Section 3 demonstrates the inefficiency of unconditional property rights. Section 4 studies the conditions under which property rights should be enforced, and discusses how our results relate to the current economic literature on property rights. Section 5 discusses some key applications and illustrations of the model. Section 6 concludes.

\section{The model}

\subsection{Sequential exchange}

The economy consists of three risk-neutral players, $\mathrm{P}$ [principal], A [agent], and T [third party], who interact in four stages, and an asset owned by $\mathrm{P}$ at the outset of play. There are both gains from specialization and gains from trade. Regarding specialization, we assume the asset's value to $\mathrm{P}$ is $v-k$ if $\mathrm{P}$ controls it, and $v$ if $\mathrm{P}$ delegates control to $\mathrm{A}$, where $k$ measures the benefits of separating asset ownership and control (e.g., Fama and Jensen, 1983). To keep the notation simple, we normalize $v=1$. Regarding the gains from trade, we assume that T's valuation of the asset exceeds P's valuation by $x>0 .^{2}$ Importantly, we assume only $\mathrm{A}$, not $\mathrm{P}$, has the skills or time necessary to sell the asset to $\mathrm{T}^{3}$ In a property context, the asset may be land or real estate, $\mathrm{P}$ an absentee landlord, A a tenant, and $k$ may measure A's ability to maintain and

\footnotetext{
${ }^{2}$ In section 4.4 we explore the case where principal P may value the asset more than the third party $\mathrm{T}$.

${ }^{3}$ We have in mind situations where there are specialization advantages. For instance, $\mathrm{P}$ needs a manager to run P's firm because P does not have either the skills or the time to negotiate directly with clients. Explicit modeling of an alternative technology (such that $\mathrm{P}$ can contact $\mathrm{T}$ directly) would not change the trade-offs we identity. It would add a simple observation - that is, when transaction costs resulting from the agency problems we analyze are too burdensome, then P may prefer to bypass A and contact T directly. However, this is a very unrealistic possibility given the overwhelming preponderance of agency relations.
} 
improve the estate. In a company context, A will be the manager of P's firm, and $k$ the managerial diseconomies that arise if $\mathrm{P}$ monitors $\mathrm{A}$, or manages the firm on his own.

In the first stage of the model, $\mathrm{P}$ decides whether to separate ownership and control of the asset (hereafter, to "specialize"). If P does so, in the second stage, which we call the "originative" contract, he may formally authorize A to sell the asset, subject to the condition that A must transfer him the price. (For instance, $\mathrm{P}$ may specify in the contract that A's authorization is valid only if A asks T to transfer the sale price directly to P's bank account). P may also promise to pay a bonus $b$ to $\mathrm{A}$ if A performs. In the company example, $b$ may be a standard managerial incentive bonus, or a sale commission. In the property example, $b$ may be a part of the real estate's price that $\mathrm{P}$ gives to $\mathrm{A}$ as a "kickback" in exchange for finding a good buyer.

In the third stage, which we call the "subsequent" contract, A may negotiate the sale of the asset to $\mathrm{T}$, in exchange for a payment $t$ (we assume that $\mathrm{T}$ pays upfront and receives the asset on the spot from $\mathrm{A}$, who is in possession of the asset). If A sells the asset, he may transfer T's payment to $\mathrm{P}$ or keep it. If A keeps the payment, $\mathrm{P}$ does not pay bonus $b$ and A's payoff is given by $t-l$, where $l$ is an inverse measure of A's opportunism, and may be due to the risk of penalties (including criminal sanctions) and reputational losses, or in a company context, to A's limited ability to autonomously invest the firm's funds. (Allowing for $l$ to depend on $x$, the gains from trade, would not affect our qualitative results). To make the model interesting, we assume A is opportunistic to some degree-formally, A would keep the price for sure if it equaled the entire surplus from trade: $1+x>l$.

Finally, if A enters an unauthorized contract with $\mathrm{T}$, in the fourth stage, a judge will allocate the asset to either $\mathrm{P}$ or $\mathrm{T}$, assigning an indemnity claim 
against A to the loser. ${ }^{4}$ Using the language of property law (Merrill and Smith 2000; Hansmann and Kraakman 2002), we will say that if the judge assigns the asset to $\mathrm{P}$ and a claim against $\mathrm{A}$ to $\mathrm{T}, \mathrm{P}$ has a "property" (or in rem) right over the asset. Conversely, if the judge assigns the asset to $\mathrm{T}$ and a claim against $\mathrm{A}$ to $\mathrm{P}, \mathrm{P}$ has a "personal" (or in personam) right over the asset.

\section{Switching the roles of $A$ and $T$}

In our baseline model, A sells P's asset to T. In an alternative specification, empirically interesting but analytically equivalent, A may be a buyer and T a seller. That is, A may buy goods from T on credit, offering P's asset as a guarantee of payment. For instance, in a company context, the asset may be the cash of P's firm of which A is a manager.

\subsection{Assumptions}

There are three key assumptions in our model. The first one is

A1: $\mathrm{T}$ does not observe the originative contract before signing the subsequent contract with A.

Assumption A1 implies that when A offers $\mathrm{T}$ to sell her the asset, $\mathrm{T}$ does not know whether A has the authority to do so. There is no loss of generality since the model's results would continue to hold under the weaker assumption that $\mathrm{T}$ may observe the originative contract at a cost (for instance, by conducting a "due diligence" investigation, as in Ayotte and Bolton, 2011).

The second key assumption is that $\mathrm{A}$ has limited liability. In particular, we assume for simplicity that A has no wealth, and hence zero liability.

A2: A has zero liability.

\footnotetext{
${ }^{4}$ We model a perfect court (there is no verifiability problem in our analysis). The consideration of partial indemnity claims might affect the incentives of $\mathrm{P}$ and $\mathrm{A}$, but it would not eliminate the possibility of collusion, which is central to our model and is defined and discussed below.
} 
This assumption has two implications. First, it ensures that a personal claim against $\mathrm{A}$ is worthless. Together with A1, this implies that P's and T's payoffs following an unauthorized sale depend on whether $\mathrm{P}$ has a property right over the asset. The second implication of $\mathrm{A} 2$ is that $\mathrm{P}$ must use the bonus $b$ both to split the sale's surplus with A (participation constraint) and to induce A to offer P's preferred sale contract to $\mathrm{T}$ (incentive constraint). As we shall see, this may limit P's control over A in equilibrium. All of the model's results would continue to hold if $\mathrm{A}$ had positive but small enough wealth.

Note that A1 and A2 capture in a simple and tractable way two central features of impersonal markets, in which participation is not limited to closelyknit communities of individuals who know each other well (A1), nor to agents who have enough personal wealth to effectively bond their transactions (A2). ${ }^{5}$

The third and last assumption is that if $\mathrm{P}$ has a property right and reclaims the asset following an unauthorized sale, buyer $\mathrm{T}$ cannot recover the sale price from P. For instance, it may be hard for T to satisfy the standard of proof and show in court that A is P's agent or that $\mathrm{T}$ bought in good faith (i.e., without knowing the sale was unauthorized). ${ }^{6}$

A3: $T$ cannot reclaim the price from $P$ following an unauthorized sale.

As we shall see in a moment, this assumption creates an interesting tradeoff between the property and personal right solutions because, by enabling $\mathrm{P}$ and $\mathrm{A}$ to collude against $\mathrm{T}$, it makes the property right solution potentially costly. In section 5.4 we relax this assumption and analyze how the model changes when $\mathrm{T}$ may be able to recover the price from $\mathrm{P}$.

\footnotetext{
${ }^{5}$ At the same time, we should emphasize that A's ability to keep the proceeds does not come from a standard lack of verifiability (since in our model there is contractual verifiability), but rather from limited liability (in both civil and criminal cases).

${ }^{6}$ Our model fits the general principles of contract law in this matter. See Peel (2007), at p. 782, "A person who is alleged to have contracted on behalf of another may, on the true construction of the contract, have contracted solely on his own behalf. In that case he alone is liable on the contract: the reason why the other is not liable is not that he is an undisclosed principal whose liability is excluded, but that he is not a principal in the transaction at all."
} 


\subsection{Timeline}

The timing of the model is summarized below. Figures 1 and 2 show the three players' payoffs under the alternative assumptions that $\mathrm{P}$ has a property or a personal right over the asset, respectively.

1. Specialization: $\mathrm{P}$ chooses whether to separate ownership and control of the asset. If he does not, the game ends, and $\mathrm{P}$ receives a payoff of $1-k$, whereas $\mathrm{A}$ and $\mathrm{T}$ receive a payoff of zero. If $\mathrm{P}$ separates ownership and control, the game moves to stage 2 .

2. Originative contract: $\mathrm{P}$ chooses whether to authorize A to sell the asset and the size of A's bonus, $b$.

3. Subsequent contract: A chooses which contract to offer T (including the price) and whether to keep the negotiated price, $t$. If A offers no contract or T rejects A's offer, the game ends, and P receives a payoff of 1 , while $\mathrm{A}$ and $\mathrm{T}$ receive a payoff of zero. If $\mathrm{A}$ sells to $\mathrm{T}$ and transfers the price to $\mathrm{P}, \mathrm{A}$ receives a payoff of $b$. If A sells and keeps the price, A receives a payoff of $t-l$. P's and T's payoffs following a sale depend on whether the sale is formally authorized and (for P) whether A transfers the price to P. In particular, if the sale is authorized and $\mathrm{A}$ transfers the price to $\mathrm{P}, \mathrm{T}$ receives a payoff of $1+x-t$, while $\mathrm{P}$ receives a payoff of $t-b$. If the sale is authorized but $\mathrm{A}$ keeps the price, $\mathrm{T}$ still receives $1+x-t$, but $\mathrm{P}$ receives a payoff of zero. Finally, if the sale is not formally authorized, P's and T's payoffs are determined at the fourth, and final, enforcement stage.

4. Enforcement: If $\mathrm{A}$ and $\mathrm{T}$ have entered an unauthorized sale at stage 3, the judge may assign the asset to $\mathrm{P}$ (granting $\mathrm{P}$ a property right) or to $\mathrm{T}$ (granting $\mathrm{P}$ a personal right). If the judge assigns the asset to $\mathrm{P}, \mathrm{T}$ receives a payoff of $-t$, whereas $\mathrm{P}$ receives a payoff of 1 if $\mathrm{A}$ has kept the price, and a payoff of $1+t-b$ if $A$ has transferred the price to 
him. If instead the judge assigns the asset to $\mathrm{T}, \mathrm{T}$ receives a payoff of $1+x-t$, whereas $\mathrm{P}$ receives a payoff of zero if $\mathrm{A}$ has kept the price, and a payoff of $t-b$ if $\mathrm{A}$ has transferred the price to him.

Figure 1. The payoffs when $\mathrm{P}$ has a property right over the asset

\begin{tabular}{|l|c|c|c|}
\hline & P's payoff & A's payoff & T's payoff \\
\hline If P does not specialize & $1-k$ & 0 & 0 \\
\hline If P specializes: & & & $1+x-t$ \\
Authorized sale, A keeps price & 0 & $t-l$ & $1+x-t$ \\
$\begin{array}{l}\text { Authorized sale, A transfers price to } \\
\text { P }\end{array}$ & $t-b$ & $b$ & $-t$ \\
Unauthorized sale, A keeps price & 1 & $t-l$ & $-t$ \\
$\begin{array}{l}\text { Unauthorized sale, A transfers price } \\
\text { to P }\end{array}$ & $1+t-b$ & $b$ & 0 \\
$\begin{array}{l}\text { No sale (A does not offer or T } \\
\text { rejects) }\end{array}$ & 1 & 0 & \\
\hline
\end{tabular}

Notice that in the property-right case, if $\mathrm{P}$ does not authorize the sale but $\mathrm{A}$ nevertheless sells to T, $\mathrm{P}$ and A split the price through the bonus $b$ (as in the case where the sale is authorized). This formulation captures in reduced form the fact that $\mathrm{P}$ and A may collude against $\mathrm{T}$ - that is, $\mathrm{P}$ may not formally authorize A to sell the asset, while privately arranging for A to sell on his own name, and for $\mathrm{P}$ and $\mathrm{A}$ to split the price through a spot (and hence selfenforcing) exchange where A gives $t$ to $\mathrm{P}$ and $\mathrm{P}$ gives $b$ to $\mathrm{A}$. To keep the notation simple, we do not model this collusive agreement explicitly but embed it in the definition of the payoffs. Also for simplicity, we denote A's share of the price as $b$ both when it is the formally contracted bonus in an 
authorized sale and when it is a privately agreed bribe in a non-authorized sale resulting from the collusion between $\mathrm{P}$ and $\mathrm{A}$. In section 4.4 we relax the assumption of perfect collusion by allowing for $\mathrm{T}$ to partially recover the price from $\mathrm{P}$ in case of unauthorized sale, and we show that the key insight from our model is still valid when collusion is endogenous.

Figure 2. The payoffs when $\mathrm{P}$ has a personal right over the asset

\begin{tabular}{|l|c|c|c|}
\hline & P's payoff & A's payoff & T's payoff \\
\hline If P does not specialize & $1-k$ & 0 & 0 \\
\hline If P specializes: & & & \\
Authorized sale, A keeps price & 0 & $t-l$ & $1+x-t$ \\
Authorized sale, A transfers price to & $t-b$ & $b$ & $1+x-t$ \\
P & 0 & $t-l$ & $1+x-t$ \\
Unauthorized sale, A keeps price & $t-b$ & $b$ & $1+x-t$ \\
Unauthorized sale, A transfers price \\
to P
\end{tabular}

\subsection{The benchmark case where property rights are irrelevant}

Suppose assumptions A1 and A2 are relaxed, so that $\mathrm{T}$ has complete information about which contracts A has been authorized to enter, and A has unlimited liability. Then, irrespective of whether $\mathrm{P}$ has a property right, T's payoff from buying the asset at price $t$ is $1+x-t$. The reason for this result is that if $\mathrm{P}$ has no property right, $\mathrm{T}$ is guaranteed to keep the asset, whereas if 
$\mathrm{P}$ has a property right and the sale is not authorized, $\mathrm{T}$ can sue $\mathrm{A}$ for the forgone profit. Thus, $\mathrm{T}$ is happy to buy the asset so long as the price is lower than the asset's value to her:

$$
1+x-t \geq 0
$$

A has no incentive to offer an unauthorized contract to T, or to keep the price, for if he did so, unlimited liability would prompt $\mathrm{P}$ or $\mathrm{T}$ to sue him for damages. If $\mathrm{P}$ authorizes $\mathrm{A}$ to sell, $\mathrm{A}$ is willing to do so, and to transfer the price to $\mathrm{P}$, in exchange for a small bonus $b \approx 0$.Thus, irrespective of whether he has a property right, $\mathrm{P}$ maximizes his payoff by authorizing the sale at price $t=1+x$. This analysis proves the following proposition.

Proposition 1: If $\mathrm{T}$ has complete information on the originative contract and $\mathrm{A}$ has unlimited liability, the first best is achieved irrespective of whether $\mathrm{P}$ has a property right over the asset.

Proposition 1 is a direct consequence of the Coase theorem. With complete information on the originative contract and unlimited liability - a hypothetical situation that approaches a small world of local, personal markets - and given that no other transaction costs are present in the model, efficient exchange can be achieved under any institutions governing the allocation of assets. In that case, our sequential exchange environment would be equivalent to an environment where $\mathrm{P}$ contracts directly with $\mathrm{T}$, as assumed in most of the economics of contracts. Only under these narrow conditions, which are not satisfied in impersonal markets, it is sensible to disregard the differences between property/real and contractual/personal rights, as most economic analyses do.

In the rest of the paper we show how given T's incomplete information about the originative contract (assumption A1) and A's limited liability (assumption A2), the equilibrium outcome depends on whether P has a 
property right, and that enforcing property rights may or may not be efficient, depending on the circumstances. ${ }^{7}$

\section{Unconditional property rights}

We begin by analyzing two polar cases that correspond to the main legal solutions. In the first one, the law unconditionally enforces property rightsthat is, in case of unauthorized sale, the judge gives the asset to $\mathrm{P}$ and grants $\mathrm{T}$ a mere personal claim against A. In the second case, the law does not enforce property rights - that is, in case of unauthorized sale, the judge gives the asset to $\mathrm{T}$ and grants $\mathrm{P}$ a personal claim against $\mathrm{A}$.

\subsection{Equilibrium concept and strategies}

Formally, we analyze pure-strategy perfect Bayesian equilibria (PBEs) of the incomplete information game between $\mathrm{P}, \mathrm{A}$ and T. In our game, P's strategy consists of four actions - namely, whether to specialize at stage 1, and whether to authorize A to sell, what sale price $t$ to authorize, and what bonus $b$ to offer, at stage 2 .

A's strategy consists of two actions, both taken at stage 2-namely, which sale price to ask $\mathrm{T}$, and if $\mathrm{T}$ accepts, whether to keep the price or to transfer it to P. Finally, T's strategy consists of one action-namely, whether to accept or reject A's offer. In the event that A makes her an offer $t$, $\mathrm{T}$ also has a belief about A's contractual status - that is, about whether A has been authorized to make such an offer. We denote T's belief that A is authorized to make offer $t$ as $\mu(t) \in[0,1]$, and T's belief that $\mathrm{A}$ is not authorized as $1-\mu(t)$.

\footnotetext{
${ }^{7}$ Note that, if $\mathrm{T}$ had incomplete information and A unlimited liability-that is, if A2, but not A1, were relaxed-, P's and T's personal claims against A would suffice to create proper incentives irrespective of who gets the asset in case of conflict. In that case, the first best would be achieved regardless of property rights as in proposition 1 . If $\mathrm{T}$ had complete information and A limited liability - that is, if A1, but not A2, were relaxed, the first best could still be achieved, but only by giving $\mathrm{P}$ a property right, or else $\mathrm{T}$ would buy the asset from A even if he observed the sale to be unauthorized. This point will become clearer from the analysis in section 4.
} 
Note that there are two major analytical differences between our model and standard incomplete information games. First, the status of the informed party (A) - which contract A is authorized to enter-is endogenous. Second, and most important, A's status is chosen by $\mathrm{P}$, rather than by the informed party himself as in models of adverse selection with endogenous types (e.g., Netzer and Scheuer 2010).

\subsection{Case 1: Property rights are always enforced}

If $\mathrm{T}$ knows that $\mathrm{P}$ will be given the asset in case of conflict, she is exposed to the risk of entering an unenforceable contract with A. Given A's limited liability, this possibility has unraveling consequences for trade, as shown by the following result.

Proposition 2: If property rights are unconditionally enforced, there is no PBE with trade.

Proof: We proceed by backwards induction. At stage 3, T accepts a contract offered by A if, and only if the expected gain, given T's belief that the contract is authorized, exceeds the expected loss:

$\mu(t)(1+x-t)-[1-\mu(t)] t \geq 0$.

Thus, if A has control of the asset, he sells it to $\mathrm{T}$ at the highest feasible price:

$t^{P R} \equiv \mu\left(t^{P R}\right)(1+x)$.

A transfers such price to $\mathrm{P}$ if, and only if the bonus offered by $\mathrm{P}$ is higher than A's payoff from keeping the price:

$b \geq t^{P R}-l$

Since A has limited liability, the minimum incentive compatible bonus is:

$b^{P R} \equiv \max \left\{t^{P R}-l, 0\right\}$ 
At stage 2, given A's and T's strategies, it is optimal for P not to formally authorize A to sell. If $\mathrm{P}$ authorizes, he optimally sets price $t^{P R}$ and bonus $b^{P R}$ in the originative contract, earning a payoff of $t^{P R}-b^{P R}=$ $\min \left\{l, t^{P R}\right\}$. If $\mathrm{P}$ does not authorize (the collusive strategy), his payoff rises to $1+\min \{l, \mu(1+x)\}$.

Anticipating that, $\mathrm{P}$ specializes at stage 1. By doing so, $\mathrm{P}$ receives the collusive premium, $\min \{l, \mu(1+x)\}$, whereas if $\mathrm{P}$ retained control of the asset, he would receive no collusive premium and would lose the gains from specialization, $k$.

But then, the only possible equilibrium belief for $\mathrm{T}$ is that no sale be authorized: $\mu(t)=0$, for all $t$. Hence, there are only two PBEs-one where A gives the asset for free to T, $\mathrm{P}$ pays no bonus, and $\mathrm{P}$ re-claims the asset; and another one where A does not even offer the asset to T. Either way, P ends up keeping the asset and the gains from trade are not realized.

As a result of Proposition 2, the total surplus when property rights are unconditionally enforced is equal to one:

$S^{P R} \equiv 1$

$\mathrm{P}$ uses the legal system to protect his asset, thereby preserving the gains from specialization, $k$, but the potential gains from trade, measured by $x$, are not realized. This result is reminiscent of Ayotte and Bolton (2011), who show that a creditor will ration funds to an entrepreneur if his cost of investigating the entrepreneur's previous credit contracts is high enough.

Proposition 2 illustrates the special kind of adverse selection that occurs in a sequential exchange environment. On one hand, due to limited liability, the informed party (A) sends his "message" (the sale price) to the uninformed party (T) irrespective of his contractual status (his authority to sell the asset). On the other hand, A's status is endogenously chosen by a third player (P) 
who benefits from not authorizing A to sell because the enforceability of property rights makes it profitable for $\mathrm{P}$ and $\mathrm{A}$ to collude against $\mathrm{T}$. These two features induce T not to trade. Notice that A's limited liability also rules out standard signaling solutions to this problem (e.g., Spence 1973 and related literature), as A cannot commit to incur a cost in case of an unauthorized sale. Moreover, P cannot either effectively commit not to collude with A: for instance, authorizing A to sell and asking him to show the authorization to $\mathrm{T}$ would not work, given the possibility for P to privately modify such authorization.

\subsection{Case 2: Property rights are never enforced}

In this case, $\mathrm{T}$ knows that if she buys from $\mathrm{A}$, any hidden owner has a personal claim against $\mathrm{A}$, but no property right over the asset. Thus, $\mathrm{T}$ will keep the asset irrespective of whether the sale is authorized or not. Anticipating that, at stage 3, $\mathrm{T}$ behaves as in a game of complete information - that is, she buys the asset if, and only if condition (1) holds:

$$
1+x-t \geq 0
$$

Given T's strategy, if A controls the asset, he sells it at the maximum price consistent with (1), $t^{P E}=1+x$. If A transfers the price to $\mathrm{P}$, his payoff following such sale is given by the incentive bonus, $b$. In contrast, if A keeps the price, his payoff is given by the price minus A's cost of being opportunistic: $1+x-l$. Hence, it is optimal for $\mathrm{A}$ to transfer the price to $\mathrm{P}$ if, and only if the bonus exceeds A's gain from being opportunistic:

$b \geq 1+x-l$.

The minimum bonus consistent with A's incentive compatibility constraint (2) and with limited liability is thus given by:

$$
b^{P E} \equiv 1+x-l .
$$


Given T's and A's strategies, and given that in the absence of property rights, $\mathrm{P}$ cannot reclaim the asset, $\mathrm{P}$ 's payoff only depends on whether he specializes at stage 1 , and on the bonus he offers to $\mathrm{A}$ at stage 2. If $\mathrm{P}$ specializes, it is optimal for him to pay A the minimum bonus $b^{P E}$ and earn the payoff:

$$
1+x-b^{P E}=l \geq 0 .
$$

P's payoff under this strategy is larger the larger A's loss from behaving opportunistically, $l$, and hence, the lower the bonus $b^{P E}$ that is necessary to motivate A to transfer the sale price to $\mathrm{P}$.

If instead $\mathrm{P}$ chooses to protect the asset by not specializing, his payoff is the value of the asset without the gains from specialization, $1-k$. Hence, in the absence of property rights, P's optimal strategy is to specialize in exchange for a share of the price (the bonus) if, and only if the gains from specialization are large relative to A's opportunism:

$$
l>1-k \text {. }
$$

If A's cost of being opportunistic is large enough, so that the difference between the sale price and the bonus needed to motivate A (the left-hand side in 3) is larger than P's payoff when ownership and control are not separated (the right-hand side), $\mathrm{P}$ will efficiently specialize, and trade will occur. Otherwise, $\mathrm{P}$ will not specialize, trade will not occur, and in addition, the gains from specialization (parameter $k$ ) will be lost.

This analysis proves our next result.

Proposition 3: If property rights are unenforceable, there is a unique PBE. In this PBE, A sells the asset to $\mathrm{T}$ when 3 holds, whereas trade does not occur, and the gains from specialization are lost, when 3 does not hold.

Let $s \in\{0,1\}$ be an indicator for whether 3 holds $(s=1)$ or not $(s=0)$, as a function of the parameters. Then, the total surplus when $P$ has a personal right can be written as: 
$S^{P E} \equiv s(1+x)+(1-s)(1-k)$.

Since trade is efficient, proposition 3 implies that when there are no property rights (only personal claims), the first best is achieved if, and only if 3 holds - that is, if $s=1$.

\section{Conditional property rights}

The analysis conducted so far shows that in our sequential exchange environment, given T's incomplete information on the originative contract and A's limited liability, both unconditional enforcement of property rights and unconditional refusal to enforce them may be inefficient. In this section, we show that efficiency can be improved by conditioning the enforcement of property rights to verifiable information.

\subsection{Property rights conditional on explicit consent}

Consider a mechanism whereby at stage $1, \mathrm{P}$ makes his originative contract with A public. Doing so in a way that guarantees that the published information cannot be manipulated ex post may be costly (see section 5.3) but, if feasible, it removes the informational asymmetry that $\mathrm{T}$ suffers when contracting with A, thereby potentially restoring efficiency. To illustrate the benefits of such an explicit "public notice" mechanism, we analyze a version, consistent with observed practice, where in case of conflict between $\mathrm{P}$ and $\mathrm{T}$, the asset is allocated solely based on the originative contract published by $\mathrm{P}$, that is, disregarding any other contract between A and P that they may have kept private.

Definition: under a right-switching mechanism (RSM), $\mathrm{P}$ is given the asset in case of conflict if the contract published by $\mathrm{P}$ does not authorize the sale between $\mathrm{A}$ and $\mathrm{T}$, whereas $\mathrm{T}$ is given the asset if the contract published by $P$ authorizes the sale. 
RSM corrects both of the inefficiencies that arise under unconditional property rights. On one hand, it removes P's incentive to collude with A-that is, to specialize, thus making it seem that A has authority to sell, while denying such authority in a private originative contract in order to later reclaim the asset. On the other hand, RSM removes T's incentive to buy regardless A's authority, which arises in the absence of property rights, thereby making it safe for P to specialize. In particular, notice that under RSM, P would publicly make A's authorization to sell contingent on T transferring the price to P's account, so T would not accept to pay A directly and consequently, A could not act opportunistically.

Proposition 4: RSM implements the first best level of trade.

Proof: We prove our proposition by showing that given RSM, there is a unique PBE where: (1) P specializes, publishes a contract authorizing A to sell the asset at price $t=1+x$ and have $\mathrm{T}$ transfer the price to $\mathrm{P}$, and offers A a small bonus, $b \approx 0$; (2) A offers the authorized sale terms to T; and (3) T accepts A's offer. Notice first that if P chooses (1), (2) and (3) are the unique best responses for $\mathrm{A}$ and $\mathrm{T}$ : given (1), $\mathrm{T}$ is better off buying because RSM insures that she will keep the asset, and A is better off selling, having the price transferred to $\mathrm{P}$ and getting a small bonus than not selling and getting zero. Notice next that $\mathrm{P}$ has no incentive to deviate from (1). On one hand, P cannot gain by authorizing A to sell at a different price or by paying a different bonus, because $1+x$ is the highest price acceptable for $\mathrm{T}$, and zero is the lowest bonus acceptable for A. On the other hand, $\mathrm{P}$ cannot gain by prohibiting the sale, because if he did so, RSM implies that $\mathrm{T}$ would never buy from A for fear of losing the asset that. We have thus proved that (1)-(3) describe a unique PBE 


\subsection{Property rights conditional on implicit consent}

Suppose explicit mechanisms for the publication of consent, such as RSM, are not available or are too costly to implement. We now show that even in this case, efficiency may be improved by conditioning property rights to verifiable evidence on P's implicit consent to sell, although the first best may not be achieved. ${ }^{8}$

Proposition 3 implies that if the law grants $\mathrm{P}$ a mere personal claim against A, rather than a property right on the asset, efficient trade occurs in equilibrium only if 3 holds - that is, if $P$ prefers separating ownership and control of the asset, thus preserving the gains from specialization at the cost of sharing the gains from trade with A. If 3 does not hold, trade fails as in the case where property rights are unconditionally enforceable, but the total surplus is even lower because, lacking such legal protection, $\mathrm{P}$ loses the gains from specialization to keep control of the asset and prevent the sale. This suggests that in the absence of explicit mechanisms like RSM, the enforcement of property rights should in some cases depend on environment characteristics that provide evidence of whether 3 holds - that is, of whether P has implicitly consented to the sale.

Proposition 5: In the absence of explicit mechanisms for publishing P's consent, enforcing property rights is efficient if and only if the 3 condition does not hold.

Proof: absent public notice mechanisms, enforcing property rights is efficient if, and only if it achieves a higher total surplus than would be achieved if property rights were not enforced: $S^{P R}>S^{P E}$, or $1>$

\footnotetext{
${ }^{8}$ Opting for simplicity for expositional reasons, we model implicit consent in a deterministic way. An alternative specification could introduce random provision of informal evidence (by means of a signal) and make the results derived in proposition 5 depend on additional thresholds.
} 
$s(1+x)+(1-s)(1-k)$. This condition is satisfied when 3 does not hold $(s=0)$, whereas it is not satisfied when 3 holds $(s=1)$.

\subsection{Explicit vs. implicit mechanisms}

Our analysis so far shows that it is more efficient to condition property rights to evidence of the owner's explicit, rather than implicit, consent. A tradeoff between these two types of evidence arises under the more realistic assumption that producing evidence of explicit consent is feasible but costly. To illustrate, assume that mechanisms such as RSM have a fixed cost $f$, as in Arruñada and Garoupa (2005). ${ }^{9}$ This could be interpreted as a direct setup cost - for instance, the expenses necessary to build a registry office and train its personnel — or as an indirect cost—for instance, the increased rent-seeking power of bureaucrats, as emphasized by Djankov et al. (2002). Conditioning property rights to explicit evidence is efficient if, and only if it generates higher total surplus than the surplus that could be obtain by conditioning on evidence of implicit consent, as determined by proposition 5:

$$
\begin{aligned}
& 1+x-f>1+s x, \text { or } \\
& (1-s) x>f .
\end{aligned}
$$

Proposition 6: Conditioning property rights on evidence of P's explicit consent is efficient if the gains from trade, $x$, are large, if the cost of producing such evidence, $f$, is low, and if the likelihood that $\mathrm{P}$ would specialize in the absence of property rights, $s$, is low.

Proof: by inspection of (4).

\footnotetext{
${ }^{9}$ The fixed cost $f$ should be understood as a reduced form. For instance, besides the cost of setting up a registry, relying on a public registry may reduce anonymity and privacy.
} 


\subsection{Possible extensions}

As discussed in section 4.5 below, our parsimonious model is sufficient to generate a tradeoff that has broad relevance and can explain a variety of core economic institutions. At the same time, our framework is tractable and thus could be readily extended to explore how including additional forces in the model, or relaxing some of its assumptions, may affect the optimal enforcement of property rights. While fully pursuing these extensions is beyond the scope of this article, we briefly discuss some of them in this section.

\section{Ex ante investment in the asset}

In a first extension, $\mathrm{P}$ may have the opportunity to make a noncontractible, asset-specific investment ex ante, which would be discouraged in the absence of property rights because of A's "holdup". This extension would not alter the tradeoffs and predictions in our model. However, adding ex ante specific investments to the model would strengthen the case for enforcing property rights, the case being more relevant when P's productive investment is significant.

\section{Uncertain gains from trade}

In a second extension, the existence of gains from trade may be uncertain, as in other economic models of property rights (e.g., Guerriero, 2016). This could be easily formalized using the notation of our model by assuming that the gains from trade equal $x>0$ with probability $p$, and $-x$ with probability $1-p$. As above, such an extension does not alter the qualitative tradeoffs we analyze here. However, it generates the additional insight that when the gains from trade are small, enforcing property rights may be preferable to the personal right solution even when the latter preserves specialization (that is, even if 3 holds). To see this formally, note that the property right solution is 
efficient if, and only if it generates higher expected joint surplus than the personal right solution, that is:

$$
S^{P R}=1>p s(1+x)+(1-p) s(1-x)+(1-s)(1-k)=S^{P E} .
$$

If 3 does not hold ( $s=0$ ), condition (5) above implies that the property right solution is efficient, as in proposition 5. However, condition (5) implies that unlike in proposition 5 , if 3 holds $(s=1)$ the property right solution may still be efficient, provided that gains from trade are unlikely to arise- that is: $p<0.5$. The conclusion is intuitive since uncertain gains imply that trade is not always efficient as considered in the baseline model.

\section{Imperfect collusion}

In a final extension, assumption A3 could be relaxed to analyze transactional environments where collusion in the property rights regime is imperfect - that is, where following an unauthorized sale, $\mathrm{T}$ can recover at least part of the price from P. A simple way of formalizing this idea would be to assume that $\mathrm{T}$ can recover a fraction $\alpha \in[0,1]$ of the price (A3 in our baseline model implies that $\alpha=0$ ). Given that T's risk is now smaller, his reservation price in the property right solution (equation 1) rises to:

$$
t^{*}=\frac{\mu\left(t^{*}\right)(1+x)}{1-\left(1-\mu\left(t^{*}\right)\right) \alpha}, \text { increasing in } \alpha .
$$

P knows that if he colludes with A (i.e., does not authorize A to sell, gets the price from $\mathrm{A}$, reclaims the asset, and pays $b^{P R}=t^{*}-l$ to $\mathrm{A}$ ), he will have to refund $\alpha t^{*}$ to T, receiving a net payoff of $1+(1-\alpha) t^{*}-b^{P R}=l+1-$ $\alpha t^{*}$. Therefore, $\mathrm{P}$ chooses the collusive strategy if, and only if the collusive payoff is higher than $l$, the payoff from authorizing the sale: $l+1-\alpha t^{*}>l$, or:

$$
\mu\left(t^{*}\right)<\frac{1-\alpha}{\alpha x} .
$$

Notice that $\mathrm{P}$ is less likely to collude if $\mathrm{T}$ believes $\mathrm{A}$ to be authorized $\left(\mu\left(t^{*}\right) \approx 1\right)$ because in that case A will sell to $\mathrm{T}$ at a high price (condition 6 ), 
and hence P's refund bill will also be high. The key point here is that if (7) holds for $\mu\left(t^{*}\right)=1$, collusion is a dominant strategy for $\mathrm{P}$, so proposition 2 continues to apply and the gains from trade are not realized. This will occur if $\mathrm{T}$ cannot recover too much of the sale price from $\mathrm{P}$ :

$$
a<\frac{1}{1+x} \equiv \bar{\alpha}
$$

If instead $\alpha=1$, P prefers not to collude even for $\mu\left(t^{*}\right)=0$, so the property right equilibrium is equal to the personal right equilibrium described by proposition 3 . In that case, the second best tradeoff between the property and personal right solutions analyzed in section 5.2 disappears. Notice, however, that proposition 4 still applies: a public notice mechanism like RSM increases efficiency because it induces $\mathrm{T}$ to refuse unauthorized sales, thereby preventing A from offering such sales in the first place.

Finally, if $a \in(\bar{\alpha}, 1)$, it is easy to check that there are two possible property right equilibria - one with collusion and no trade (as in proposition 2), and one without collusion (as in proposition 3).

Our baseline model, where $a=0$, should therefore be seen as a normalization for the more general case where $a<\bar{\alpha}$. We leave refinements of the multiple equilibria case $(a \in(\bar{\alpha}, 1))$ for future consideration.

\subsection{Contribution to the literature}

Our paper relates to the vast economic literature on property rights initiated by Coase (1960), and continued by Demsetz (1967), Barzel (e.g., Barzel, 1997), Hart (e.g., Grossman and Hart, 1986), and many others (e.g., Libecap, 1993; see also Lueck and Miceli, 2007, and Segal and Whinston, 2013, for recent reviews). Defining property as the right to use and dispose of an asset, much of this literature focuses on how allocating property rights to one or the other party in a bilateral transaction may affect ex ante investments in the asset (e.g., Grossman and Hart, 1986; Hart and Moore, 1990; 
Holmstrom and Milgrom, 1991, 1994), and the two parties' ability to bargain over its transfer ex post (e.g., Matoushek, 2004; Segal and Whinston, 2016).

Relative to this literature, our paper brings two central features of modern impersonal markets into the analysis, which importantly affect the role of property rights. The first feature is what we label "sequential exchange": the potential buyer of rights on an asset ( $\mathrm{T}$ in our model) may not know whether the seller (A) has been authorized by the asset's initial owner $(\mathrm{P})$ to transfer such rights; thus, the relevant transaction to be analyzed is (at elast) tri-lateral, rather than bilateral. The second feature of impersonal markets incorporated by our model is limited liability (assumption A2): it may not be credible for the state to impose efficient penalties on a seller (A) if he expropriates the owner of an asset (P) by selling it against the latter's will. ${ }^{10}$

In this environment, the key attribute of property rigths is not that they assign (residual) rights of control, but rather, that they "run with the asset", which is thus assigned to the owner $(\mathrm{P})$, and not to the uninformed acquirer (T), in case of unauthorized transactions (Merrill and Smith 2000; Hansmann and Kraakman 2002; Arruñada, 2003). Moreover, whether property rights should be enforced depends on whether the ex ante gains from specialization $(k)$ are large enough to induce the owner to delegate control of the asset and thus enable its future transfer. If that is the case, enforcing the owner's property rights against future buyers prevents the gains from trade $(x)$, and hence is not optimal. Otherwise, enforcing property rights allows the owner to protect the asset while maintaining separation of ownership and control, and hence is optimal.

A few recent papers have developed economic models of property rights in sequential exchange environments (Medina, 2003; Ayotte and Bolton, 2011;

\footnotetext{
${ }^{10}$ When there are no liability constraints, the efficient sanctions against expropriation may be stronger or weaker depending on the relative importance of promoting ex ante investment or ex post bargaining (e.g., Kaplow and Shavell, 1996; Bar-Gill and Persico, 2016; Guerriero, 2016; Segal and Whinston, 2016).
} 
and Dari-Mattiacci et al., 2016). As explained below, these papers importantly differ from ours in terms of analytical results, applications, and scope. Both Medina (2003) and Dari-Mattiacci et al. (2016) study the sale of stolen goods to a good faith purchaser. Medina (2003) shows that if the owner is entitled to restitution, the buyer's willingness to pay decreases, while his incentive to investigate the goods' origin may increase. Thus, depending on which effect dominates, it may be more efficient to allow the buyer to keep the goods. DariMattiacci et al. (2016) develop a model where the good's price and the probability of theft are endogenously determined, and show that in such a context, value allocation is more important than incentive inducement. The main difference between these papers and ours is that by focusing on buyer incentives as the key benefit of property rights, they are not well suited to analyze complex property and company transactions where buyer investigation is unlikely to be feasible or effective.

Closer to our article, Ayotte and Bolton (2011) develop a model where an entrepreneur's assets serve as collateral for two sequential loans. They show that under a legal rule granting prior enforcement to the earlier loan (akin to our "property right" solution), the entrepreneur has an incentive to keep it hidden, forcing the second creditor to conduct due diligence or bear risk. This may cause credit rationing, while at the same time preventing excess lending. Like us, Ayotte and Bolton (2011) explicitly model a tri-lateral, sequential exchange environment, and find that a major cost of enforcing property rights is a reduction in trade. However, in their model the choice between the property right and personal right solutions solves a tradeoff between two different ex post inefficiencies - that is, too little trade under property rights (no lending by the second creditor in a good state) and too much trade under personal rights (lending by the second creditor even in a bad state). In our model, instead, the key tradeoff is beween ex post and ex ante inefficienciesnamely, too little trade under property rights ( $\mathrm{T}$ does not buy the asset from A, and the gain $x$ is not realized), and no separation of ownership and control 
under personal rights ( $\mathrm{P}$ may not delegate control of the asset to $\mathrm{A}$, in which case the gain from specialization $k$ is not realized). ${ }^{11}$ As discussed below, bringing the ex ante gains from specialization, and the owner's endogenous decision to separate ownership and control, into a sequential exchange framework is important, because it allows us to explain property rights enforcement in a variety of non-financial property and company transactions that the Ayotte and Bolton (2011) model cannot capture.

\section{Applications}

There are two key insights from our theoretical analysis. First, when parties contracting over an asset cannot observe previous "originative" contracts, optimal property rights solve a tradeoff between ex ante gains from specialized asset management (which call for enforcing property rights) and ex post gains from trade (which calls for enforcing personal rights). Second, conditioning the enforcement of property rights to public evidence of the originative contract overcomes the tradeoff and is therefore efficient, provided that the cost of producing such evidence is low relative to the gains from specialization and trade. In this section we discuss how our theoretical framework applies to, and sheds light on key market institutions underlying both company and property transactions.

\subsection{Property and company registries}

Consistent with our analysis, the enforcement of property rights is often contingent on institutions that provide public evidence of past contracts over the underlying assets. In a company context, historically, a contract entered by a manager used to commit its company - that is, shareholders lost their property rights over the company's assets — only if such commitment fell

\footnotetext{
${ }^{11}$ As discussed in section 4.4, our model can be easily extended to allow for "too much trade" (the case where $x<0$ ) without affecting our key tradeoff of interest.
} 
within the scope of the manager's authorization, as filed in a public registry (Armour and Whincop 2007; Arruñada 2010). Today, this happens even without any explicit filing, but only if the manager is - depending on the jurisdiction - registered as a manager or publicly acting as such. Similarly, in the context of land, the law typically grants rightholders (owners, mortgagees) a property right - that is, a right valid against subsequent acquirers of competing property rights in the same land-only in the presence of verifiable evidence of their holding. In old times, this evidence used to be produced, for ownership, through the public delivery of possession, as in the Roman mancipatio ceremony (Arruñada, 2015). However, possession is out of the question for abstract rights such as mortgages - a main reason behind the creation of public property registries (e.g., Arruñada 2003; Arruñada and Garoupa, 2005).

As mentioned above, our framework also suggests that the enforcement of property rights should be contingent on explicit/registered - as opposed to implicit/unregistered - evidence of the owners' consent (or lack thereof) only if the cost of developing and maintaining registries is small relative to the gains from specialization and trade. This prediction is also consistent with the broad historical evolution of property and company institutions. In particular, the evidence to establish whether unauthorized contracts entered by a manager do or do not commit the company has switched from implicit consent (apparent authority) to explicit consent (describing the manager's authority or merely recording of her appointment in a company registry) as the scope and size of markets and trade has expanded. In a similar vein, property registries as an explicit mechanism to define property rights over land are more developed and successful in advanced market economies. By making impersonal trade viable, these institutions make it easier to break the limits of local and personal markets that characterize traditional and less-developed economies. 
By advocating a comparative analysis of the costs and benefits of publicity mechanisms, our paper also sheds new light on the debate on property and business institutions initiated by De Soto (1989) and Djankov et al. (2002), and reflected in policy initiatives like the Doing Business Project. This literature emphasizes the rent-seeking costs of "formalizing" business companies via institutions such as company registries and echoes the belief that they are entry barriers. However, it hardly considers the benefits of such institutions as important facilitators of trade. As a result, this literature advocates the simplification, if not outright elimination, of formalization procedures. However, a simplified formalization procedure-for instance, a "ministerial" company registry with limited verification- provides less information to market participants on hidden originative contracts, who then must spend more resources in verification and may be subject to greater manipulation ex post (e.g., Arruñada and Manzanares 2016). If that is the case, our model suggests that simplifying formalization procedures may not be optimal when the gains from trade are large. As to straightforward elimination, our model conclusively suggests that such policy is not likely to be efficient.

More broadly, our analysis suggests that both the costs and the benefits of formalization should be factored into institutional design. At the same time, it also suggests that there may be considerable value in the development of technologies that produce reliable public evidence on originative contracts without generating the direct and indirect costs of the existing formalization mechanisms. This conclusion is consistent with the current interest in applying the blockchain technology beyond Bitcoin.

\subsection{The law of good faith purchase}

As documented by numerous scholars (e.g., Medina, 2003; Arruñada 2010, 2012; Schwartz and Scott 2011), when a seller sells an asset to an innocent buyer, the law generally allows the buyer to keep the asset in case of conflict with the original owner - that is, the owner loses his property right - if the 
seller is a "merchant" (e.g., UCC 2-403 in the U.S., the "market overt" rule in England and other European countries). However, this principle does not typically apply for used goods stores, art galleries, and auction or pawn shops.

Both the general good faith purchase rule and its exceptions appear to be efficient according to our theory. In particular, a merchant is less likely to steal goods from their owner (or to buy and resell stolen goods) than a nonmerchant seller or a pawnbroker because if he did so, he would lose his reputation. Thus, when the seller is a merchant it is a priori more likely that the original owner appropriates the gains from trade, and hence that he/she has efficiently separated ownership and control by entrusting the good to the seller. Accordingly, it is efficient for the law to presume delegation, and refuse to enforce the owner's property rights against innocent buyers, when the seller is a merchant, and to presume lack of delegation, and enforce the owner's property rights, when the seller is a pawnbroker.

\subsection{Adverse possession}

Adverse possession implies that an owner loses property rights over his assets to a good faith possessor, provided that the latter's possession is notorious and has lasted for a long enough period (e.g., Lueck and Miceli, 2007). This implies that an adverse possessor can sell the assets to third parties, who will be allowed to keep them in case the original owner claims them back. Thus, in the language of our paper, adverse possession implies that relative to subsequent transactions with third parties, the original owner's property rights are enforced if possession of the seller has lasted less than the critical time threshold, but are turned into mere personal claims against the seller if possession has lasted beyond the time threshold.

The time threshold that triggers adverse possession has been observed to vary across both legal systems (e.g., Guerriero, 2016) and transaction characteristics. Regarding the former, there is evidence that the number of 
years necessary to trigger adverse possession is greater in US states with lower land development value (Netter et al., 1986; Baker et al., 2001). Regarding transaction characteristics, it is well known that in Classical Roman law (i.e., within a given legal system) the time necessary to trigger adverse possession (usucapio) of provincial land was longer (longi tempori praescriptio) when the original owner and the possessor were not in the same district (Arruñada 2015).

Our theoretical framework provides a joint efficiency explanation for both the adverse possession principle and the patterns of variation of time terms described above. Regarding the general principle, the legally established time term can be interpreted as the time the original owner has to notice and revoke undesired possession if he/she wants to do so. Then, possession beyond the term indicates that the owner has consented to leave the possessor in control of the asset. If the time term is appropriately chosen, our theory suggests that it is efficient to enforce the original owner's property rights, even against third parties who may have acquired the asset from the possessor if, and only if, possession has not lasted more than the time term. That is exactly what the law does.

Regarding the time term's patterns of variation, note first that, all else equal, if the original owner and the possessor reside in different districts, it is more difficult for the owner to get notice and repossess the asset. Therefore, it is less likely that possession for a given number of years indicates voluntary delegation of the asset's control to the possessor, or to put it differently, the critical time term such that voluntary delegation can be presumed is longer. This is consistent with the longer term for different-district as opposed to same-district adverse possession in Roman law. Moving to the crossjurisdictional evidence, lower land development value indicates lower gains from the specialized management of land. This suggests that holding the years of possession constant, separation of land ownership and possession is less 
likely to be voluntary in those jurisdictions, and hence the time threshold necessary to presume voluntary separation should be longer. This is consistent with the US empirical evidence. ${ }^{12}$

\section{Conclusion}

This article has studied property rights in a realistic market and institutional environment, where the acquirer of rights over an asset may not know whether the agent selling those rights has been authorized to do so by the owner, an essential element in productive specialization. In this setting, a key feature of property rights is that they can be enforced against subsequent acquirers, or in rem. This has been largely ignored in the economic literature by assuming that economic agents enjoy unlimited liability, and hence that the difference between property and personal rights is not a key aspect of enforcement.

We fill this gap by showing that in a setting where agents suffer from limited liability, if property rights are unconditionally enforced, assets cannot be exchanged due to the information asymmetry faced by market participants. In contrast, if property rights are not enforced, inefficient concentration of asset ownership and control may occur, wasting specialization possibilities. To overcome this tradeoff, property rights must be conditioned on explicit evidence of the owner's consent to transfer the asset. In the absence of mechanisms for making the owner's consent public, property rights should be conditioned on implicit evidence that the owner has voluntarily delegated control of the asset to the agent. The baseline tradeoff we have identified is robust to different analytical specifications and extensions.

Our model thus provides a unified rationale for the institutional underpinnings of specialization and the separation of ownership and control-

\footnotetext{
12 This evidence (but not the Roman evidence) can also be explained by alternative theories. See, for instance, the discussion by Lueck and Miceli (2007, p. 226).
} 
a central feature of market economies at least since the analysis of Adam Smith (1776). In particular, our model highlights how specialization is made possible by a panoply of complex and sometimes misunderstood institutions, such as adverse possession, the rules on good faith purchase, and property and company registries. Our model also provides an analytical framework that may be useful to adapt these institutions without hampering their fundamental market-preserving function.

Our parsimonious model could be enriched to allow for multiple assets as well as multiple owners, agents and traders enjoying different specialization opportunities and suffering different degrees of asymmetric information caused by the more or less strict enforcement of property rights. This more general model could be used to study economic development and growth as a function of property rights institutions, as well as their distributive consequences. While these extensions are outside the scope of the present paper, we hope to pursue them in future research.

\section{References}

ACEMOGLU, D. (2003), "Why Not a Political Coase Theorem? Social Conflict, Commitment, and Politics," Journal of Comparative Economics 31: $620-652$.

ACEMOGLU, D., S. JOHNSON, and J. ROBINSON (2001), “The Colonial Origins of Comparative Development: An Empirical Investigation," American Economic Review 91: 1369-1401.

AKERLOF, G. (1970), “The Market for 'Lemons’: Quality Uncertainty and the Market Mechanism,” Quarterly Journal of Economics 84: 488-500.

ALDASHEV, G., and G. ZANARONE (2017), "Endogenous Enforcement Institutions," Journal of Development Economics (forthcoming). 
ARMOUR, J., and M. WHINCOP (2007), "The Proprietary Foundations of Corporate Law,” Oxford Journal of Legal Studies 3: 429-465.

ARRUÑADA, B. (2003), "Property Enforcement as Organized Consent," Journal of Law, Economics and Organization 19: 401-444.

ARRUÑADA, B. (2010), "Institutional Support of the Firm: A Theory of Business Registries," Journal of Legal Analysis 2: 1-52.

ARRUÑADA, B. (2012), Institutional Foundations of Impersonal Exchange, Chicago: University of Chicago Press.

ARRUÑADA, B. (2015), “The Titling Role of Possession,” in CHANG, Y. (ed.), The Law and Economics of Possession, Cambridge: Cambridge University Press, 207-233.

ARRUÑADA, B., and N. GAROUPA (2005), "The Choice of Titling System in Land," Journal of Law and Economics 48: 709-727.

ARRUÑADA, B., and C. MANZANARES (2016), "The Tradeoff Between Ex Ante and Ex Post Transaction Costs: Evidence from Legal Opinions," Berkeley Business Law Journal, 13: 217-55.

AYOTTE, K., and P. BOLTON (2011), “Optimal Property Rights in Financial Contracting," Review of Financial Studies 24: 3401-3433.

BAIRD, D., and T. JACKSON (1984), "Information, Uncertainty, and the Transfer of Property,” Journal of Legal Studies 13: 299-320.

BAKER, M., T. MICELI, C. SIRMANS, and G. TURNBULL, (2001), "Property Rights by Squatting: Land Ownership Risk and Adverse Possession Statutes," Land Economics 77: 360-370.

BAR-GILL, O., and N. PERSICO (2016), "Exchange Efficiency with Weak Ownership Rights," American Economic Journal: Microeconomics 8:230267. 
BARZEL, Y. (1997), Economic Analysis of Property Rights, Cambridge: Cambridge University Press.

BESLEY, T. (1995), "Property Rights and Investment Incentives: Theory and Evidence from Ghana," Journal of Political Economy 103:903-37.

NORTH, D., and R. THOMAS. 1973. The Rise of the Western World: A New Economic History. Cambridge: Cambridge University Press.

COASE, R. (1960), “The Problem of Social Cost,” Journal of Law and Economics 3: 1-44.

DARI-MATTIACCI, G., C. GUERRIERO, and Z. HUANG (2016), “The Property-Contract Balance," Journal of Institutional and Theoretical Economics 172: 40-64.

DEMSETZ, H. (1967), “Toward a Theory of Property Rights,” American Economic Review 57: 347-359.

DE SOTO, H. (1989), The Other Path: The Invisible Revolution in the Third World, New York: Harper \& Row.

DE SOTO, H. (2000), The Mystery of Capital: Why Capitalism Triumphs in the West and Fails Everywhere Else, New York: Basic Books.

DJANKOV, S., R. LA PORTA, F. LOPEZ-DE-SILANES, and A. SHLEIFER (2002), “The Regulation of Entry," Quarterly Journal of Economics 117: 1-37.

ELLICKSON, R. C, and C. D. THORLAND (1995), “Ancient Land Law: Mesopotamia, Egypt, Israel," Chicago-Kent Law Review, vol. 71, no. 1, pp. 321-411.

FAMA, E., and M. JENSEN (1983), "Separation of Ownership and Control," Journal of Law and Economics 26: 301-325. 
GREIF, A., P. MILGROM, and B. WEINGAST (1994), "Coordination, Commitment, and Enforcement: The Case of the Merchant Guild," Journal of Political Economy 102: 745-776.

GROSSMAN, S., and O. HART (1986), “The Costs and Benefits of Ownership: A Theory of Vertical and Lateral Integration," Journal of Political Economy 94: 691-719.

GUERRIERO, C. (2016), “Endogenous Property Rights," Journal of Law and Economics 59: 313-358.

HART, O., and J. MOORE (1990), "Property Rights and the Nature of the Firm,” Journal of Political Economy 98: 1119-1158.

HANSMANN, H., and R. KRAAKMAN (2000), “The Essential Role of Organizational Law," Yale Law Journal 110: 387-440.

HANSMANN, H., and R. KRAAKMAN (2002), "Property, Contract, and Verification: The Numerus Clausus Problem and the Divisibility of Rights,” Journal of Legal Studies 31: S373-S420.

HOLMSTROM, B., and P. MILGROM (1991), "Multitask Principal-Agent Analysis: Incentive Contracts, Asset Ownership, and Job Design," Journal of Law, Economics and Organization 7: 24-52.

HOLMSTROM, B., and P. MILGROM (1994), "The Firm as an Incentive System," American Economic Review 84: 972-991.

KAPLOW, L., and S. SHAVELL (1996), "Property Rules versus Liability Rules: An Economic Analysis," Harvard Law Review 109: 713-790.

KRANTON, R., (1996), "Reciprocal Exchange: A Self-Sustaining System,” American Economic Review 86: 830-851.

LIBECAP, G. (1993), Contracting for Property Rights, Cambridge: Cambridge University Press. 
LUECK, D., and T. MICELI (2007), "Property Rights and Property Law," in POLINSKY, M., and S SHAVELL (eds.), Handbook of Law and Economics, vol. 2, ch. 3.

MATOUSCHEK, N. (2004), "Ex Post Inefficiencies in a Property Rights Theory of the Firm," Journal of Law, Economics and Organization 20: 125-147.

MEDINA, B. (2003), "Augmenting the Value of Ownership by Protecting it Only Partially: The Market-Overt Rule Revisited," Journal of Law, Economics and Organization 19: 343-372.

MERRILL, T., and H. SMITH, (2000), "Optimal Standardization in the Law of Property: The Numerus Clausus Principle," Yale Law Journal 110: 170.

NETTER, J., P. HERSCH, and W. MANSON, (1986), “An Economic Analysis of Adverse Possession Statutes," International Review of Law and Economics 6: 217-227.

NETZER, N., and F. SCHEUER (2010), “Competitive Markets without Commitment," Journal of Political Economy 118: 1079-1109.

NORTH, D., and R. THOMAS (1973), The Rise of the Western World: A New Economic History, Cambridge: Cambridge University Press.

NORTH, D., J. WALLIS, and B. WEINGAST (2009), Violence and Social Orders: A Conceptual Framework for Interpreting Recorded Human History, Cambridge: Cambridge University Press.

OLSON, M. (1993), "Dictatorship, Democracy, and Development," American Political Science Review 87: 567-576.

PEEL, E. (2007), Treitel on the Law of Contract, $12^{\text {th }}$ edition, London: Sweet \& Maxwell. 
SCHWARTZ, A., and R. SCOTT (2011), "Rethinking the Laws of Good Faith Purchase," Columbia Law Review 111: 1332-1383.

SEGAL, I., and M. WHINSTON (2013), "Property Rights," in GIBBONS, R., and J. ROBERTS (eds.), Handbook of Organizational Economics, Princeton: Princeton University Press, 100-158.

SEGAL, I., and M. WHINSTON (2016), "Property Rights and the Efficiency of Bargaining," Journal of the European Economic Association 14: 1287 1328.

Smith, Adam. ([1776] 1981), An Inquiry into the Nature and Causes of the Wealth of Nations, Indianapolis: Oxford University Press/Liberty Press.

SPENCE, M. (1973), “Job Market Signaling,” Quarterly Journal of Economics 87: 355-374.

WILLIAMSON, O. (1979), "Transaction Cost Economics: The Governance of Contractual Relations," Journal of Law and Economics 22: 233-261. 